\title{
The Role of Social Presence in Cross-Border e-Commerce Accounts on Commitment
}

\author{
Yu-Ping Wu*, Hong Jin, Chih-Hsuan Huang \\ Hubei University of Economics, China. \\ * Corresponding author. Tel.: 86-18571582948; email: 2434519927@qq.com \\ Manuscript submitted March 1, 2017; accepted August 12, 2017. \\ doi: 10.17706/ijeeee.2018.8.1.34-43
}

\begin{abstract}
While online shopping websites are facing the difficulties of price and low-quality competition, cross-border online shopping is on a vigorous development trend, showing that cross-border shopping is an important trend of online shopping field. To provide a deeper understanding of how cross-border e-commerce accounts can effectively engage consumer, this study examines the social aspects of the cross-border e-commerce context by focusing on social presence. The aim of this study is to provide the development marketing strategy and product positioning in the future. This study investigates the relationships among satisfaction, trust, social presence, affective commitment and calculative commitment. Though an experiment with 908 Ali express users, the study finds that all hypotheses are supported. Social presence is formed through emotion value, social value, and monetary value; that greater social presence increases users' satisfaction and their trust in the company. The findings indicate the differential influence of various antecedents on affective and calculative commitment, and highlight the role played by these forms of commitment on consumption satisfaction and trust. The results demonstrate the importance of affective commitment as a relationship enhancer, and identify managerial implications for customer commitment to cross-border e-commerce accounts.
\end{abstract}

Key words: Cross-border e-commerce, perceived value, social presence, affective commitment, calculative commitment.

\section{Introduction}

More and more Chinese consumers enjoy internet shopping because of strong economic growth and rapid internet penetration. Furthermore, they are enthusiastic buyers of foreign products using foreign online retailers. China's cross-border e-commerce is a new pattern of cross-border trade which takes electronic as means. The rapid development of cross-border trade is inseparable from promoting e-commerce platform. Currently, there are some platform which could provide service of cross-border e-commerce in China, including Amonza, ebay and Ali express. It has grown at the exceptionally fast rate of 74.8 per cent annually from 2011 and reached about US $\$ 600 \mathrm{bn}$ market size according to the China Internet Network Research Center (2016). In a recent survey by Nielsen, 32 per cent Chinese respondents had experienced purchasing overseas goods online, and a PayPal survey found cross-border shopping will grow to 130 million consumers by 2018, including 36 million from China. Alibaba started operating www.tmall.hk in February 2014, which is a business-to-customer (B2C) model haitao business. Amazon.cn also started its haitao business in November 2014. Gmarket.co.kr initiated haitao service from 2013 and invested aggressively because of rapid sales growth in 2013. 
Cross-border e-commerce creates new market spaces and provides differentiated values for Chinese customers. Building and managing good relationships with Cross-border e-commerce users have become increasingly critical to business's marketing efforts and sustainability. Customers' perceived value is often deemed as the key factor most drastically influencing the behavioral outcome in the course of decision-making of purchase. The customers' assessment before purchase, continual use after purchase or the value perceived via customers will all further influence the future purchase intention. Therefore, the higher value perceived by the customer is, the higher expectation will produce in customers, and the purchase intention will also be stronger. In the past research, few scholars discuss about the users' perceived value of using technology products. However, in the context of using cross-border e-commerce, customers' perceived value will provide some key successful factors to obtain the users' attention and promote to continue their downloading or purchase.

To advance such understanding, we focus on social presence, which has been shown to play an important role in providing satisfying interactions and relationship building in computer-mediated communication. In a cross-border e-commerce content, social presence has also been found to be a significant antecedent of increased interaction and gratification of social connection need. We adopt social presence formation to examine the effect of those communication characteristics on the formation of social presence. It can help us better understand how well-managed communications leveraged by cross-border e-commerce characteristics can lead to engaging and sustained relationships between cross-border e-commerce accounts and users. Among lots of researches concerning e-commerce, many scholars classify commitment into two different dimensions of affective commitment and calculative commitment, mainly focus on the consideration in affective and economic dimension between each other. In terms of customers, in addition to the factors of identity or dependence degree, they still need to assess the loss or cost produced by transformation, so as to consider whether to continue to maintain the relationship with the products or service. Commitments is recognized as a key precursor to the attainment of valuable outcomes, such as disconfirmation process, future intentions and profitability.

\section{Conceptual Framework}

\subsection{Perceived Value}

Sweeny and Soutar [1] thought that perceived value is the satisfaction coming from different customers. In respect of the customers' assessment in the value of products or service, on one hand, the customers' expected performance and money value for products or service are required to be considered, on the other hand, the sense of pleasure and fun produced or brought by customers' use of products or service, as well as the social identity and sense of belonging conveyed by products or service to others are required to be included. This research adopted the four values proposed by [1] to discuss the customers' opinions of function value, emotional value, social value and money value in the context of using the cross-border e-commerce account program, which will be used as the basis to measure customers' perceived value in this study.

\subsection{Social Presence}

Social presence theory focuses on the degree to which communicating parties in a mediated environment perceive one another in terms of being a "real person" [2]. Social presence is the extent to which a medium allows users to experiences others as being psychologically present.

Social presence can help overcome these potential problems by increasing peer connections. When individuals are connected they are more likely to attend more deeply to messages and to see the value of the messages and the ideas and contributions of others [3]. 
In the cross-border e-commerce context, social presence has been employed to evaluates the relational aspects between users and websites. Creating a virtual shopping experience that will entice the masses must engage the cognitive and social sides of the customers.

\subsection{Satisfaction}

An effectively designed website may engage and attract online consumers resulting in satisfaction with an online vendor [4]. In other research, website design and the "ambience associated with the site itself and how it functions" is an antecedent to satisfaction. In this research, website satisfaction refers to overall contentment with the online experience [5] including access to information, a positive navigation experience, and perception of a well-designed website. Repeated satisfaction with a vendor eventually results in e-loyalty.

However, in other work and consistent to predictions in the current investigation, satisfaction was found to directly impact customer e-loyalty. Through these stronger connections, individuals should be more likely to trust and satisfaction the e-commerce company as well as shopping more.

\subsection{Trust}

Trust is a key concept in interactions and important for companies in developing bonds with sellers [6] Ref. [7] define trust as one's confidence on the exchange party's capability and willingness to establish the business' adherence to the relationship norms, and keep promises. Trust is viewed as a unidimensional or multidimensional concept. However, a better understanding of trust benefits from the recognition of its dimensions. Cognitive and affective trusts are major types of trust. Cognitive trust is the customer's belief in and willingness of dependency on an exchange partner's ability and consistency. Affective trust is a customer's belief about a firm's level of care and concerns based on emotions. Both cognitive and affective trusts contain dimensions of credibility (one's belef that the exchange party is reliable) and benevolence (beliefs that the exchange partner is motived by seeking joint again.

Prior e-commerce research has focused on finding key antecedents of trust or disclosing the trust building mechanism. These studies focused more on the impacts of functionality (e.g. usability, ease of use and usefulness) and institutional structures (e.g. structural assurance, situational normality and feedback mechanisms), paying very little attention to social factors except social presence of web interface. Trust, indeed, is built through social interactions with other people and the surrounding environment. Thus, social context should be an important but neglected characteristic of trust in prior literature.

The lack of face-to face interactions could result in customers' suspicion of truthfulness in online exchanbges and the paucity of knowledge about the e-commerce could further heighten the adverse influence of risk in online shopping. It is noteworthy that trust in the website can be facilitated by customer reviews and experiences posted in forums and communities.

\subsection{Commitment}

Morgan and Hunt [8] thought that commitment and trust have the close relation. When the commitment between the two parties appears, it is important for one of the two parties to identify the relationship between each other. Thus, they will spare no effort to maintain this relationship.

Commitment is classified into affective commitment and calculative commitment, which is proposed by [9]. Affective commitment refers to that sellers and buyers spare no effort to maintain the relationship between each other thanks to the delighted cooperative experience in the past. Also, the two parties enjoy the emotional attachment and sense of identity brought by such partnership. Calculative commitment refers to continuously maintaining the relationship due to involving switching cost or lacking the other alternatives. In the literature concerning word-of-mouth effect of online tourism websites researched by 
Nusair, Hua, \& Li, commitment is classified into two dimensions of affective commitment and calculative commitment, and commitment is deemed as the important and key intervening variable between satisfaction and word-of-mouth. The nature of service in mobile software store is transaction. This transaction platform is a kind of typical e-commerce platform.

\section{Hypothesis Development}

\subsection{The Effect of Perceived Value on Social Presence}

Perceived value is the essential result of marketing activates and is a first-order element in relationship marketing. It is understood as a construct configured by two parts, one of benefits received (economic, social and relationship) and another of sacrifices made (price, time, effort, risk and convenience) by the customer. Transferring the experiential view to the study of the perceived value construct, two conclusions can be drawn. Firstly, the view of perceived value as a cognitive variable is partial, since it is necessary to incorporate the affective component. Secondly, social presence is the importance of the component in which the technology enables to create an environment in which they feel is warm, personal, sociable, and active. Social presence is known to shape people's physiological and psychological responses to objects in their environment. Such person interactivity in a cross-border e-commerce account give users a feeling that good experiences of consumption and helps form a sense of social presence within the cross-border e-commerce account. Thus, we hypothesize the following:

H1a: Functional value will positive influence social presence.

H1b: Emotion value will positive influence social presence.

H1c: Social value will positive influence social presence.

H1d: Monetary value will positive influence social presence.

\subsection{Social Presence and Satisfaction}

Social presence can help overcome these potential problems by increasing peer connections. When individuals are connected they are more likely to attend more deeply to messages and to see the value of the messages and the ideas and contributions of others. Through these stronger connections, individuals should be more likely to see the course as be valuable as well as learning more. This can make participating in e-environment more satisfying. However, social presence should also shape affective reactions to the environment satisfaction. Improving social presence enhance satisfaction with the e-environment. Therefore the following hypotheses were investigated:

H2a: Social presence will a positive impact on satisfaction.

\subsection{Social Presence and Trust}

The website social presence cue explores how human warmth and sociability can be integrated through the web-interface to positively influence consumer attitudes towards online shopping. Buyers conduct online transactions mainly through interacting with the website. These buyer-web interactions could be viewed similar to interpersonal interactions if the website were treated a social actor. Since human interaction is viewed as a precondition of trust the buyer-web interactions should also contribute to the building of trust online. A high social presence website conveys more information and social cues, and thus, is perceived to be more transparent; whereas in a more transparent environment the untrustworthy behaviors will be inhibited.

Thus, in a cross-border e-commerce marketplace, the social presence created by an online seller will make him/her more trustworthy. Hence, we can expect the cross-border e-commerce buyers to consider the social presence as a key developing trust to wards online shopping. Thus, the following hypothesis is proposed: 
H2b: Social presence will have a positive impact on trust.

\subsection{Commitments: The Effects of Satisfaction}

Cater and Zabkar held that when customers' satisfaction increases, they will not calculate or explore the reason for continuing to maintain the relationship between each other. Therefore, it is thought that satisfaction and calculative commitment are negatively correlated. Also, some scholars put forward that affective commitment and calculative commitment both belong to a part of commitment. Thus, it is thought that there also exits positive correlation between satisfaction and calculative commitment. In the research concerning online tourism websites, Nusair, Hua, \& Li found that customers' satisfaction has positive influence relation with affective commitment. In the research concerning service marketing relation, it is also found that customers' satisfaction has positive influence relation both on affective commitment and calculative commitment.

In the context of using cross-border e-commerce, when users feel better satisfaction towards the service provided by cross-border e-commerce company, it is better to obtain customers' affective identity and increase. Customers with more satisfaction cross-border e-commerce company seem more likely to show strong affective and calculative commitment. According, this study hypothesized that:

H3a: Satisfaction will a positive impact on affective commitment.

H3b: Satisfaction will a positive impact on calculative commitment.

\subsection{Commitments: The Effects of Trust}

Trust refers to the customers' confidence in suppliers while commitment refers to the willingness to maintain long-term cooperative relationship between two parties. In many researches concerning e-commerce, many scholars regard trust as an important factor influencing commitment, classifying commitment into two different dimensions of affective commitment and calculative commitment [9],[10]. It is also thought that trust should have significant positive influence relationship with affective commitment. Cater and Zabkar thought that trust has positive influence relationship with affective commitment and has negative relationship with calculative commitment. As trust make two parties feel the sense of identity, they are willing to actively maintain the relationship between each other, further reducing to calculate the reason for continuous maintenance of relationship between each other.

Moreover, the more a consumer trusts a online social network, the more likely he/she is to continue the relationship. Accordingly, the following hypotheses are proposed.

H4a: Trust will a positive impact on affective commitment.

H4b: Trust will a positive impact on calculative commitment.

\section{Research Methodology}

\subsection{Sample and Data Collection}

Cross-border e-commerce platforms, such as ebay, Amazon and Ali express, link users to e-vendors, however, these platforms differ based on aspects such as informational/interactional channels, privacy policies, quality/quantity of peer contents generation, economic feasibility, size, and reputation [10].

We used Ali epress as the target platform, which has about 500 million registered users on its panel and it is the largest e-commerce platform in China [11]. According to a survey conducted by CNNIC in March 2015, $63.4 \%$ of Internet users in China are of 18-30 years old and 41\% have a bachelor's degree or above. Based on the overall characteristics of Internet users in China, our survey mainly aimed at adults. It was conducted through an online survey website (www.sojump.com). A total of 1200 questionnaires were collected, and after eliminating those with incomplete information, 908 samples were used for this empirical analysis. 


\subsection{Measures}

The study adapted the existing validated scales whenever possible. Items for perceived value scale was borrowed from the stduy by [12]. Social presence was measured by the items from [6]. Items for satisfaction were based on those of [13]. The items for trust was derived from [6]. Affective commitment and calculation commitment items were adapted from [14]. All constructs were measured by multiple items based on a seven-point Likert scale ranging from "strongly disagree" to "strongly agree."

\section{Analysis}

Following procedures recommended by [15], this research conducted two analysis phases. First, the measurement model is estimated with confirmatory factor analysis (CFA) to test reliabilities and validities of the research constructs. Then, the structure model is used to test the strength and direction of the proposed relationships between researches constructs.

\subsection{Measurement Model}

To avoid common method variance problem or reduce its occurring, this research use the methods developed by [16]. Harman's single-factor test was conducted [17]. This test assumes that if the common method variance exists, then when all of the variables entered together, they will load on one single factor that will account for all of the variance, or one factor will account for a majority of the variance. This study performed the exploratory factor analysis (EFA) and four factors with eigenvalue greater than one emerged. All 42 items of the total variance was less than 50\%. In addition, this study also performed the confirmatory factor analysis (CFA) with all 42 items in the questionnaire. The model fit of the single-factor test was worse (Chi-square $=6521.104, \mathrm{D} . \mathrm{F}=629, \mathrm{GFI}=0.479, \mathrm{AGFI}=0.418, \mathrm{IFI}=0.318, \mathrm{CFI}=0.315, \mathrm{RMSR}=0.164$ ) compared with the model fit of the proposed model (Chi-square=949.083, D.F. $=605, \mathrm{GFI}=0.892$, AGFI=0.873, IFI=0.960, $\mathrm{CFI}=0.960$, RMSR $=0.074$ ). The results indicate that $\mathrm{CMV}$ is not a significant problem in this research.

Results also support for the convergent and discriminant validity. As evidence of convergent validity, each item loaded significantly on its respective construct [15]. Evidence of discriminant validity exists when the square root of the average of variance extracted (AVE) in each construct exceeds the coefficients representing its correlation with other constructs [18]. As presented in Table 1, the results indicate adequate discriminant validity.

Table 1. Discriminant Analysis for Constructs

\begin{tabular}{|c|c|c|c|c|c|c|c|c|c|c|c|}
\hline Constructs & FV & EV & SV & MV & SP & SAT & TRU & $\mathrm{AC}$ & $\mathrm{CC}$ & $\mathrm{CR}$ & AVE \\
\hline $\mathrm{FV}$ & 0.812 & & & & & & & & & 0.896 & 0.660 \\
\hline EV & $0.311^{* *}$ & 0.850 & & & & & & & & 0.912 & 0.722 \\
\hline SV & $0.149 * *$ & $0.152^{* *}$ & 0.807 & & & & & & & 0.882 & 0.652 \\
\hline MV & $0.150^{* *}$ & $0.177^{* *}$ & $0.217^{* *}$ & 0.875 & & & & & & 0.928 & 0.765 \\
\hline SP & $0.215^{* *}$ & $0.164^{* *}$ & $0.183^{* *}$ & $0.213^{* *}$ & 0.860 & & & & & 0.914 & 0.759 \\
\hline SAT & $0.196^{* *}$ & $0.210^{* *}$ & $0.174^{* *}$ & $0.243^{* *}$ & $0,226^{* *}$ & 0.812 & & & & 0.853 & 0.659 \\
\hline TRU & $0.267^{* *}$ & $0.314^{* *}$ & $0.224^{* *}$ & $0.271^{* *}$ & $0,213^{* *}$ & $0.294^{* *}$ & 0.797 & & & 0.913 & 0.636 \\
\hline $\mathrm{AC}$ & $0.171^{* *}$ & $0.179^{* *}$ & $0.168^{* *}$ & $0.244^{* *}$ & $0.221^{* *}$ & $0.274^{* *}$ & $0.277^{* *}$ & 0.784 & & 0.827 & 0.614 \\
\hline $\mathrm{CC}$ & $0.280^{* *}$ & $0.285^{* *}$ & $0.169 * *$ & $0.225^{* *}$ & $0.104^{* *}$ & $0.267^{* *}$ & $0.266^{* *}$ & $0.189 * *$ & 0.797 & 0.840 & 0.636 \\
\hline $\begin{array}{c}\text { Cronbach's } \\
a\end{array}$ & 0.874 & 0.912 & 0.876 & 0.926 & 0.825 & 0.850 & 0.910 & 0.814 & 0.838 & & \\
\hline
\end{tabular}

Note: FV: Functional Value; SV: Social Value; EV: Emotional Value; MV: Monetary Value; SP: Social Presence; SAT: Satisfaction; TRU: Trust; AC: Affective Commitment; CC: Calculative Commitment; CR: Composite Reliability; AVE: Average Variance Extracted; Diagonal value is the square root of AVE; Lower triangle value is the Pearson correlation coefficient.

${ }^{*} p<0.05 ;{ }^{* *} p<0.01 ;{ }^{* * *} p<0.001$ 


\subsection{Structural Model}

We next analyzed the structural model to examine the significance and strength of relationships of each of our hypothesized effects. The structural model provided evidence of a good model fit: $\chi 2=949.083$, D.F. $=605$, $\chi 2 / \mathrm{DF}=1.569, \mathrm{GFI}=0.891, \mathrm{AGFI}=0.873, \mathrm{RMSR}=0.054, \mathrm{RMSEA}=0.037$. Based on the suggestions of [19] and [20], the criteria of model-fit of this model would be adequate. Overall, the measurement model showed adequate fit. Fig. 1 shows that the hypotheses results and path coefficients. All hypotheses are supported with all path coefficients, $p<0.001$.

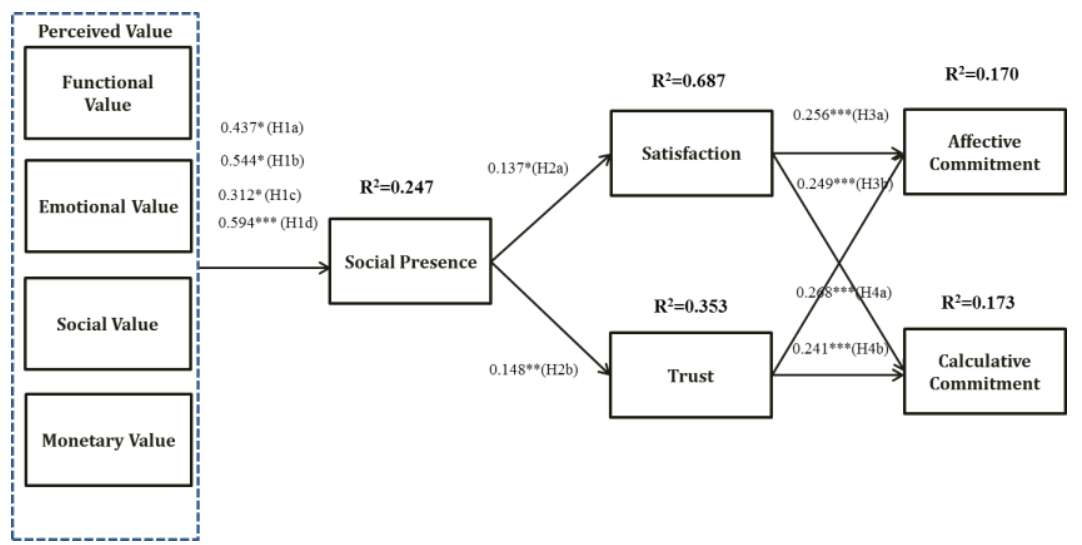

Fig. 1. Results of the structural model. ${ }^{*} p<0.1 ;{ }^{* *} p<0.05 ;{ }^{* * *} p<0.001$.

\section{Discussion and Implications}

\subsection{Discussion}

The experimental results show that function value, emotional value, social value and monetary value significantly affect social presence. They demonstrate that how the characteristics of cross-border e-commerce account are designed to interact with users and how communication in enabled by those characteristics are important in forming social presence. The more that these communications included rich cues such as VR, photographs, and communication interaction, the more participants felt social presence in the corporate cross-border e-commerce account but through the general interactivity embedded in the form design, indicating that mutual interaction is possible at a personal level and can enable interactions even with external resources. The human service component is the key ingredient for retaining customers to an online retailer. Thus, Social presence in a e-commerce gives customers a better experience that resembles a physical store. The salient effect of social presence stresses the importance of considering the social relational perspective in addition to the function, emotion, social and monetary value.

In addition, the result indicate that social presence indeed affects cross-border e-commerce users' trust and their perceptions of the satisfaction in a company and that those tw constructs affects cross-border e-commerce users' commitment to the company. In parallel. This research also offers interesting new prospects for marketing managers in term of how to lead e-commerce management in order to obtain better consumer shopping experiences.

\subsection{Theoretical and Managerial Implications}

This study accomplishes several theoretical objectives. First, the customers' perceived value is often deemed as the key factor most drastically influencing the behavioral outcome in the course of decision-making of purchase. The customers' assessment before purchase, continual use after purchase or the value perceived via customers will all further influence the future purchase intention. 
Second, this research results found that social presence has positive effect on satisfaction, trust and commitment. According to the opinions of [1], this study classified perceived value into function value, emotional value, social value and money value mainly in that the application for these four dimensions is wider and they are consistent in nature. Besides, by adopting such value classification method, it can also fully reflect the value brought by cross-border e-commerce to customers.

While the influence of social presence in various cross-border e-commerce environments has been previously investigated, relatively few studies have examined how corporate cross-border e-commerce company interact with users. Our findings show that in this context, the values that induce consumers' relationships with companies can stem from and be increased by social drives, demonstrating that users' perceptions of how trustworthy and satisfaction companies are and how useful their information is are dependent on the way corporate cross-border e-commerce accounts build the feeling of social presence through using inherent characteristics of cross-border e-commerce.

Third, the findings for the cross-border e-commerce study, the research result shows that satisfaction and trust can significantly positively influence affective commitment and calculative commitment. Satisfaction has the greatest influence on both of the antecedent factors of affective commitment and calculative commitment. It shows that the better satisfaction the users feel over the service provided by cross-border e-commerce account can better obtain the users' attachment and affective identity.

Company marketers can most effectively design communications with consumers through cross-border e-commerce. The operations of person interactivity suggests that display in the history of the footage of particular conversations and broadcasting other users' messages is a good way to show users that corporate cross-border e-commerce accounts value the conversation and that other people are also engaged in it.

Fourth, our result suggests that higher alternative attractiveness lead to higher calculative commitment toward a e-commerce company. This result can be explained through the lens of the cross-border purchase context. Unlike regular purchased products, cross-border purchases require a significant amount of monetary and emotional resource allocation for most customers. Hence Once bought, a customer may wait for a comparatively longer period for his or her net purchase. The customer may increase his commitment to the cross-border e-commerce company by advocating the company strongly. This strategy, in turn, may make his consumption appropriate in the eyes of the significant others.

These results thus have extremely important managerial implications because they suggest that, if brands want to create loyal customers, they need to work better on their communications as well as of the entire brand experience in order to generate and consolidate affective bonds with customers.

The brand management needs to be the focus of the entire organization and that it will be extremely difficulst to build superior experiences and the customers' commitment.

\subsection{Limitations and Future Research}

First, although both initial relationship building and relationship maintenance are critical to managing effective corporate communications, it is difficult to capture a continued relationship with fictitious companies created for an experiment. Second, In terms of abstract subjects, it is suggested to increase the node of network questionnaire distribution, to design the inducement for filling and to increase the investigation on preference in the behavior of downloading and purchase, downloading or purchase category and degree of willingness to pay for it, aimed at users of cross-border e-commerce account with different characteristics. Thus, the influence of relevant factors and behavioral intention can be understood and comparative analysis can be conducted with this research, so as to seek for the more reliable argumentation. Third, it is suggested to further discuss their influence factors in the future research, such as benefits, appropriateness of technology or product involvement. We hope that future research will 
investigate these issues in the area. Therefore, future research might conduct longitudinal studies to mimic real cross-border e-commerce environments in which participants can continue their relationships with real corporate cross-border e-commerce accounts.

\section{Conclusions}

This study makes several important contributions to the cross-border e-commerce literature. We contribute to the cross-border e-commerce studying in social presence mediated environment (functional value, emotion value, social value, monetary value) allows users to experience others as being psychologically present. Social presence is an effective way to increase customers' satisfaction and trust thereby help companies achieve their desired goals.

\section{Acknowledgment}

This paper is financially supported by the Humanities and Social Sciences Project, Hubei Provincial Department of Education (No:17Y089).

\section{References}

[1] Sweeny, J. C., \& Soutar, G. N. (2001). Consumers perceived value: The development of a multiple item scale. Journal of Retailing, 77(2), 203-220.

[2] Williams, E. (1977). Experimental comparisons of face-to-face and mediated communication: A review. Psychological Bulletin, 84(5), 963.

[3] Fulk, J., Steinfield, C. W., Schmitz, J., \& Power, J. G. (1987). A social information processing model of media use in organizations. Communication Research, 14(5), 529-552.

[4] Agarwal, R., \& Venkatesh, V. (2002). Assessing a firm's web presence: A heuristic evaluation procedure for the measurement of usability. Information Systems Research, 13(2), 168-186.

[5] Anderson, R. E., \& Srinivasan, S. S. (2003). E-satisfaction and e-loyalty: A contingency framework. Psychology \& Marketing, 20(2). 123-138.

[6] Gefen, D., Karahanna, E., \& Straub, D. W. (2003). Trust and TAM in online shopping: An integrated model. MIS Quarterly, 27(1), 51-90.

[7] Schurr, P. H., \& Ozanne, J. L. (1985). Influences on exchange processes: Buyers' preconceptions of a seller's trustworthiness and bargaining toughness. Journal of consumer research, 11(4), 939-953

[8] Kim, S., \& Park, H. (2013). Effects of various characteristics of social commerce (s-commerce) on consumers' trust and trust performance. International Journal of Information Management, 33(2), 318-332.

[9] Morgan, R. M., \& Hunt, S. D. (1994). The commitment-trust theory of relationship marketing. Journal of Marketing, 58(3), 20-38.

[10] Allen, N. J., \& Meyer, J. P. (1990). The measurement and antecedents of affective, continuance and normative commitment to organization. Journal of Occupational Psychology, 63(1), 1-8.

[11] Fan, Y., Ju, J., \& Xiao, M. (2016). Reputation premium and reputation management: Evidence from the largest e-commerce platform in China. International Journal of Industrial Organization, 46, 63-76.

[12] Deng, Z., Lu, Y., Wei, K. K., \& Zhang, J. (2010). Understanding customer satisfaction and loyalty: An empirical study of mobile instant messages in China. International Journal of Information Management, 30(1), 289-300.

[13] Cronin, J. J., Brady, M. K., \& Hult, G. T. M. (2000). Assessing the effects of quality, value, and customer satisfaction on consumer behavioral intentions in service environments. Journal of Retailing, 76(2), 193-218. 
[14] Li, D., Browne, G. J., \& Chau, P. Y. K. (2006). An empirical investigation of Web site use using a commitment-based model. Decision Sciences, 37(3), 427-444.

[15] Anderson, J. C., \& Gerbing, D. W. (1988). Structural Equation Modeling in practice: A review and recommended two-step approach. Psychological Bulletin, 103(3), 411-423.

[16] Podsakoff, P. M., MacKenzie, S. B., Lee, J. Y., \& Podsakoff, N. P. (2003). Common method biases in behavioral research: A critical review of the literature and recommened remedies. Journal of Applied Psychology, 88(5), 879-903.

[17] Podsakoff, P. M., \& Organ, D. W. (1986). Self reports in organizational research: Problems and prospects. Journal of Management, 12(4), 531-544.

[18] Fornell, C., \& Larcker, D. F. (1981). Evaluating structural equation models with unobservable variables and measurement error. Journal of Marketing Research, 18(1), 39-50.

[19] Jöreskog, K. G., \& Sörbom, D. S. (1993). LISREL 8, a Guide to the Program and Application. Chicago: SPSS Inc.

[20] Hair, J. F., Black, W. C., Babin, B. J., \& Anderson, R. E. (2010). Multivariate Data Analysis (7th ed.). Englewood Cliffs: Prentice-Hall.

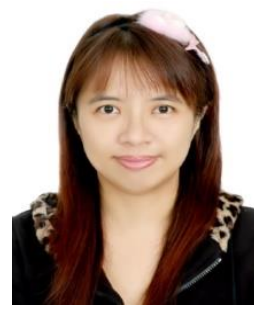

Wu Yu-Ping is a lecturer in the School of Business Administration at Hubei University of Economics, Wuhan city, China. She earned her Ph.D. degree from National Dong Hwa University in 2016. She was elected as an International Economics Development Research Center (IEDRC) senior member in March 2017. Her research areas include marketing management, e-commerce, lean service and strategic. She has published 19 papers at international and domestic academic journals and conferences.

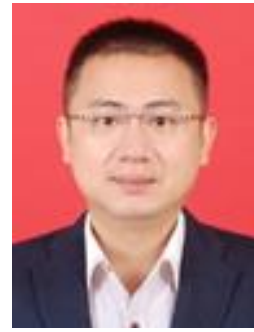

Hong Jin received his Ph.D in management science and engineering from Wuhan University of Technology, Wuhan city, China in 2011. He is an associate professor in the School of Business Administration at Hubei University of Economics (HBUE), Wuhan city, China. He is a dean of the Marketing Department in College of Business Administration at HBUE. His research interests include business model innovation, strategic innovation and management.

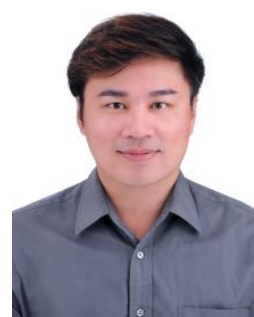

Chih-Hsuan Huang received his Ph.D. in consumer behavior from Queensland University of Technology, Brisbane, Australia in 2013. He is a Lecturer in the School of Business Administration at Hubei University of Economics, Wuhan City, China.

He was elected as an International Economics Development Research Center (IEDRC) Fellow Member in Jan. 2016. He is a Technical Program Committee for 2017 International Conference on Economic Development and Enterprise Innovation (EDEI) and 2017 International Conference on Financial Technology (ICFT). His research in these areas has appeared in a journal such as Asia Pacific Journal of Marketing and Logistics, International Journal of Health Care Quality Assurance, Journal of Management Research, Asia Journal of Business and Management, Journal of Computing and Information Science in Engineering, etc. His research interests include green consumer behavior, relationship marketing, sustainable management and patient safety. 